\title{
Use of Solid Boluses in High-resolution Manometry
}

\author{
Yu Tien Wang ${ }^{1 *}$ and Daniel Sifrim ${ }^{2}$ \\ ${ }^{1}$ Department of Gastroenterology and Hepatology, Singapore General Hospital, Singapore; and ${ }^{2}$ Barts and The London School of Medicine and \\ Dentistry, Queen Mary University of London, London, United Kingdom
}

\author{
Article: Esophageal motility in the supine and upright positions for liquid and solid swallows through high-resolution \\ manometry \\ Zhang X, Xiang X, Tu L, Xie X, Hou X \\ (J Neurogastroenterol Motil 2013;19:467-472)
}

We read with great interest the data presented by Zhang et al ${ }^{1}$ regarding changes in high-resolution manometry (HRM) values when the procedure was performed in the upright position using solid swallows. Dysphagia and other esophageal symptoms due to abnormal esophageal motility have been shown to be poorly diagnosed by clinical history or endoscopy. ${ }^{2,3}$ Assessment of esophageal manometry is advocated as the subsequent investigation. While HRM based on standard supine water swallows as described by the Chicago classification ${ }^{4}$ has been effective in guiding the management of achalasia, it has had limited impact on clinical management of other motility disorders. ${ }^{5}$ In addition, it is increasingly recognized that performing HRM in a supine position is non-physiological and poorly tolerated by some patients. Performing the investigation in an upright position results in changes in the normative values which may alter the diagnosis in some patients. ${ }^{6}$ In addition, the use of solid swallows as a provocative physiological test has been shown to increase the sensitivity of detecting motility disorders ${ }^{7}$ and has been advocated as a complementary test to the standard water swallows. ${ }^{8,9}$
The data from this Chinese cohort complements findings from other centers. ${ }^{6,10}$ The main findings of this study were as follows: compared to supine liquid swallows, the upright position produced significantly lower integrated relaxation pressure, shorter distal latency (DL) and weaker distal contractile integral (DCI) while solid swallows produced slower contractile front velocity, longer DL and stronger DCI. While there is unanimous agreement with the changes in DCI, ${ }^{6,10,11}$ there is conflicting findings with the changes in the other parameters (integrated relaxation pressure, DL and contractile front velocity). DCI is a reflection of the effort required of the esophagus to effect bolus transit; hence it is reduced in the upright position as it is aided by gravity but increased with the demand of propagating a solid or viscous bolus. The discrepancies in changes produced in the other parameters are unclear and may indeed be due to variations in study technique, patient characteristics or demographics. Indeed these studies were conducted in 3 different continents. It is also likely that despite attempts to standardize the protocol, there exist factors which are difficult to control. By way of example, during

Received: August 22, 2013 Revised: None Accepted: September 10, 2013

(c) This is an Open Access article distributed under the terms of the Creative Commons Attribution Non-Commercial License (http://creativecommons. org/licenses/by-nc/3.0) which permits unrestricted non-commercial use, distribution, and reproduction in any medium, provided the original work is properly cited.

*Correspondence: Yu Tien Wang, MD

20 College Road, Department of Gastroenterology and Hepatology, Level 3, Singapore 169856

Financial support: None.

Tel: +65-6321-3973, Fax: +65-6227-3623, E-mail: wangyutien@gmail.com

Conflicts of interest: None. 
solid swallows, the extent to which the patient has chewed the food (which alters the consistency of the swallowed bolus) and the proportion of the prescribed food which the patient swallows may vary. Nonetheless, it highlights the need for a standardized protocol and the potential need for localized normative value, as is the case in other gastrointestinal motility investigations. ${ }^{12}$

Moving forwards, we now need to investigate the relationship of "abnormal results" with corresponding symptoms and outcomes. One way of establishing this is to identify temporal associations between patient-reported symptoms with abnormal manometric events. However, our experience has been that patients often have difficulty in distinguishing their presenting complaint from the discomfort produced by the presence of the manometry catheter during stationary HRM investigations. Hence, an ambulatory $\mathrm{HRM}^{13}$ which allows patients more time to acclimatize to the sensation of the catheter, as well as conducting the study in the patient's "normal environment," may facilitate this by providing data on symptom associations similar to that of ambulatory reflux studies. Further development of the HRM equipment by reducing the diameter of the manometry catheter or developing a catheter-free system akin to the wireless capsule $\mathrm{pH}$ monitoring system ${ }^{14}$ would further improve the tolerability of the test. In conclusion, the study by Zhang et $\mathrm{al}^{1}$ has reinforced the feasibility of conducting HRM in an upright position with solid swallows. We look forward to studies which evaluate the ability of these additional tests in improving the diagnostic sensitivity and identifying underlying motility disorders. One area of research could be the utility of solid swallows in evaluating patients with post-fundoplication symptoms, where standard water swallow HRM has had limited clinical impact. ${ }^{15}$ Deploying a physiological challenge such as solid swallows may improve the sensitivity of HRM to detect relevant dysfunction and thus enable guided clinical management.

\section{References}

1. Zhang X, Xiang X, Tu L, Xie X, Hou X. Esophageal motility in the supine and upright positions for liquid and solid swallows through high-resolution manometry. J Neurogastroenterol Motil 2013;19: 467-472.
2. Klauser AG, Schindlbeck NE, Müller-Lissner SA. Symptoms in gastro-oesophageal reflux disease. Lancet 1990;335:205-208.

3. Costantini M, Crookes PF, Bremner RM, et al. Value of physiologic assessment of foregut symptoms in a surgical practice. Surgery 1993;114:780-786; discussion 786-787.

4. Bredenoord AJ, Fox M, Kahrilas PJ, et al. Chicago classification criteria of esophageal motility disorders defined in high resolution esophageal pressure topography. Neurogastroenterol Motil 2012; 24(suppl 1):57-65.

5. Anumandla A, Bethards DM, Ouyang A. Does the Chicago classification alter the management of patients with suspected esophageal motor disorders? Gastroenterology 2011;140(suppl 1):S297- S298.

6. Xiao Y, Read A, Nicodème F, Roman S, Kahrilas PJ, Pandolfino JE. The effect of a sitting vs supine posture on normative esophageal pressure topography metrics and Chicago Classification diagnosis of esophageal motility disorders. Neurogastroenterol Motil 2012;24: e509-e516.

7. Allen ML, Mellow MH, Robinson M. Manometry during food ingestion aids in the diagnosis of diffuse esophageal spasm. Am J Gastroenterol 1992;87:568-571.

8. Fox MR, Bredenoord AJ. Oesophageal high-resolution manometry: moving from research into clinical practice. Gut 2008;57:405-423.

9. Wang YT, Yazaki E, Sifrim E. High-resolution manometry: esophageal disorders not addressed by the "Chicago Classification". J Neurogastroenterol Motil 2012;18:365-372.

10. Sweis R, Anggiansah A, Wong T, Kaufman E, Obrecht S, Fox M. Normative values and inter-observer agreement for liquid and solid bolus swallows in upright and supine positions as assessed by esophageal high-resolution manometry. Neurogastroenterol Motil 2011; 23:509, e198.

11. Roman S, Damon H, Pellissier PE, Mion F. Does body position modify the results of oesophageal high resolution manometry? Neurogastroenterol Motil 2010;22:271-275.

12. Camilleri M, Bharucha AE, di Lorenzo C, et al. American Neurogastroenterology and Motility Society consensus statement on intraluminal measurement of gastrointestinal and colonic motility in clinical practice. Neurogastroenterol Motil 2008;20:1269-1282.

13. Mittal RK, Karstens A, Leslie E, Babaei A, Bhargava V. Ambulatory high-resolution manometry, lower esophageal sphincter lift and transient lower esophageal sphincter relaxation. Neurogastroenterol Motil 2012;24:40-46, e2.

14. Sweis R, Fox M, Anggiansah R, et al. Patient acceptance and clinical impact of Bravo monitoring in patients with previous failed catheter-based studies. Aliment Pharmacol Ther 2009;29:669-676.

15. Wilshire CL, Niebisch S, Watson TJ, et al. Dysphagia postfundoplication: more commonly hiatal outflow resistance than poor esophageal body motility. Surgery 2012;152:584-592; discussion 592-584. 